\title{
Restricting genome data won't stop bioterrorism
}

\section{Release of sequence information is necessary to aid defence against these pathogens.}

Sir — With the "War on Terrorism" still firmly on the political agenda, measures for increasing security against possible bioterror attacks are being hotly debated. Some proposals are common-sense security issues that have long needed addressing. Others would curtail the academic freedom of investigators working on pathogenic organisms, and inhibit research into the diseases they cause (see The Economist 362, 8263, 75-77; 2002, and Nature 414, 237; 2001).

One particular concern is whether sequencing centres should publicly release genetic sequence information of pathogenic organisms that could be used for bioterrorism. We believe restrictions on data release would compromise the ability of legitimate scientists to study these organisms and investigate new countermeasures, while offering essentially no tangible benefit to the security of the general public.

The temptation to prohibit sequence release arises from the belief that the data will be used by hostile governments, terrorist groups or even individual bioterrorists. However, most of the problems associated with producing and using biowarfare agents - such as growth, storage and dispersal — will not be assisted by genomic information. In contrast, most defensive interventions (novel drugs, vaccines and surveillance methods) could be vastly improved by genome-based technology. Many pathogens considered as theoretical biowarfare agents in the developed world are existing public health threats in the developing world. For example, Yersinia pestis still causes plague and Bacillus anthracis kills livestock. The release of data facilitates and accelerates research on these organisms to help developing countries that have limited resources but an immediate interest in stopping the spread of these diseases.

Prohibiting data release will not stop transmission of data. Like the organisms themselves, data can rapidly multiply and spread. If security is compromised and the data become available on the Internet, it will be impossible to track who has subsequent access to them - any party wishing to procure the information will eventually obtain it. Therefore, restricting data release implies tight containment: very few users in very few locations. Such an approach would be disadvantageous because the wider scientific community (overwhelmingly in favour of preventing hostile use of biowarfare organisms) could not then work on countermeasures.

Because few, if any, genomic sequencing facilities have the capability of handling classified information, draconian restrictions prohibiting release would restrict our capacity even to generate these data. If they are so dangerous, one would have to argue that they should not be generated at all. This is wrong. We should continue to distribute these data freely.

Fundamentally, the primary issue of data release is control. If genome-sequence information is not available openly to the public, it is in the control of someone else, in this case government organizations. When citizens know that the government is withholding information, they become distrustful of the motives of the scientists involved in the research. If control of information about bioterror pathogen genomes is taken from the free academic community there is also the danger of a gradual encroachment on other areas of study. This arises from fears of strain 'improvement' to make more effective bioweapons through introduction of foreign genes. Hence, many organisms not considered biowarfare pathogens but containing toxin genes (for example Vibrio, Staphylococcus and Salmonella) could be restricted because they are potential sources for bioweapons.

Scientists have been branded naïve for making available sequences of agents that could be used by terrorists. But is there a difference between releasing the sequencing data for such microbial genomes and releasing the prime target for biowarfare attacks: the human genome? Timothy D. Read ${ }^{\star}$, Julian Parkhill $\dagger$ * The Institute for Genomic Research, 9712 Medical Center Drive, Rockville, Maryland 20850, USA $\dagger$ The Sanger Institute, Wellcome Trust Genome Campus, Hinxton, Cambridge CB10 1SA, UK

\section{What's in a name? In the Middle East, everything}

Sir-Since 1994 I have been revising the species of Israel and adjacent areas of the particular insect group on which I am a specialist. For the purposes of my entomological work, I defined five areas: Gaza Strip, West Bank, Israel, Golan Heights and Sinai, which together made up the study area, and I listed the records of the various species under these geographical headings.

I defined Israel by its pre-June 1967 borders with Jordan and Syria (the "Green Line"). I referred to the Golan Heights as being in Syria, in accordance with the UN Security Council Resolution no. 497 (1981). Finally, I considered the Gaza Strip and West Bank beyond the Green Line as occupied Palestinian territory.

Because the official "Israel Touring Map 1: 250 000" does not mark a border between Israel and the occupied or annexed territories, I had to consult other maps to assign localities to the geographical entities. I mainly used the Times Atlas of the World, Comprehensive Edition (1986 and 2000), but also others, including the 1949 armistice map (available on the Internet).

I wanted to publish my manuscript in an Israeli journal because most of the material is housed by Tel-Aviv University and was collected by its staff, so I asked a member of the editorial board of the Israel Journal of Entomology to ask the editor if the journal would in principle accept my geographical terms. The answer was no: the journal would not use "unofficial territorial names" such as West Bank or Gaza Strip "as long as the boundaries in the Middle East have not been officially decided". The implication was that all the localities must be assigned to Israel.

Thus the Israel Journal of Entomology bans any mention of Palestinian national territory and forbids the use of the two names that are used for it by the world at large. Similarly, the Saudi Arabian journal
Fauna of Saudi Arabia uses the word "Palestine" instead of "Israel". This type of action is politics, not science.

\section{Knut Rognes}

Stavanger University College, PO Box 8002, $N$-4068 Stavanger, Norway

\section{Foundation's funding}

Sir - In your News story (Nature 417, 3; 2002) about the new organizations formed by Craig Venter, you say "The endowment reportedly kicks off with $\$ 100$ million of Venter's own money". To clarify, the money which will be housed in the J. C. Venter Science Foundation was from the TIGR (the Institute for Genome Research) endowment that was realized from stock Dr Venter directed to TIGR from his association with two for-profit companies. Heather E. Kowalski

TIGR Center for the Advancement of Genomics, 1901 Research Boulevard, Rockville,

Maryland 20850, USA 